\title{
Effects of omalizumab on chronic urticaria not responding to recommended therapy
}

\author{
Jacques Hébert ${ }^{1,2^{*}}$, Rose-Marie Caron-Guay ${ }^{1}$ \\ From Canadian Society of Allergy and Clinical Immunology Annual Scientific Meeting 2012 \\ Calgary, Canada. 11-14 October 2012
}

\section{Background}

Treatment of chronic urticaria consists of antihistamines as the first-line treatment. For more severe symptoms, combinations can be necessary as well as dose augmentations. The recent guidelines suggest the possibility of using omalizumab in resistant cases. We treated 2 patients with cold-urticaria $(\mathrm{CO}), 1$ with cholinergic urticaria $(\mathrm{CH})$ and 11 with chronic spontaneous urticaria (CSU) with omalizumab, who had not benefited from the recommended first-line, second-line and third-line treatments.

\section{Methods}

Patients were required to document their CU symptoms once daily with urticaria activity scores for 7 days (7UAS). Briefly, the symptoms were monitored in terms of numbers of wheals [none ( $=0$ points), $<10$ (=1 point), $10-50$ (=2 points), or $>50$ per day ( $=3$ points)], and the intensity of their pruritus [none ( $=0$ points), mild ( $=1$ point), moderate ( $=2$ points), severe ( $=3$ points)], for a total of 42 points. To evaluate the efficacy of the omalizumab treatment, 7UAS obtained at baseline was compared to that at the third and sixth month of the therapy. Omalizumab was given at $150 \mathrm{ug} / \mathrm{month}$ irrespective of IgE levels and increased to $300 \mathrm{mg}$ if needed (no response). The concomitant medication was slowly reduced according to clinical response.

\section{Results}

The 7UAS improved significantly in all severe urticaria patients with omalizumab as early as one month (not shown) after initiation of therapy and was sustained for the

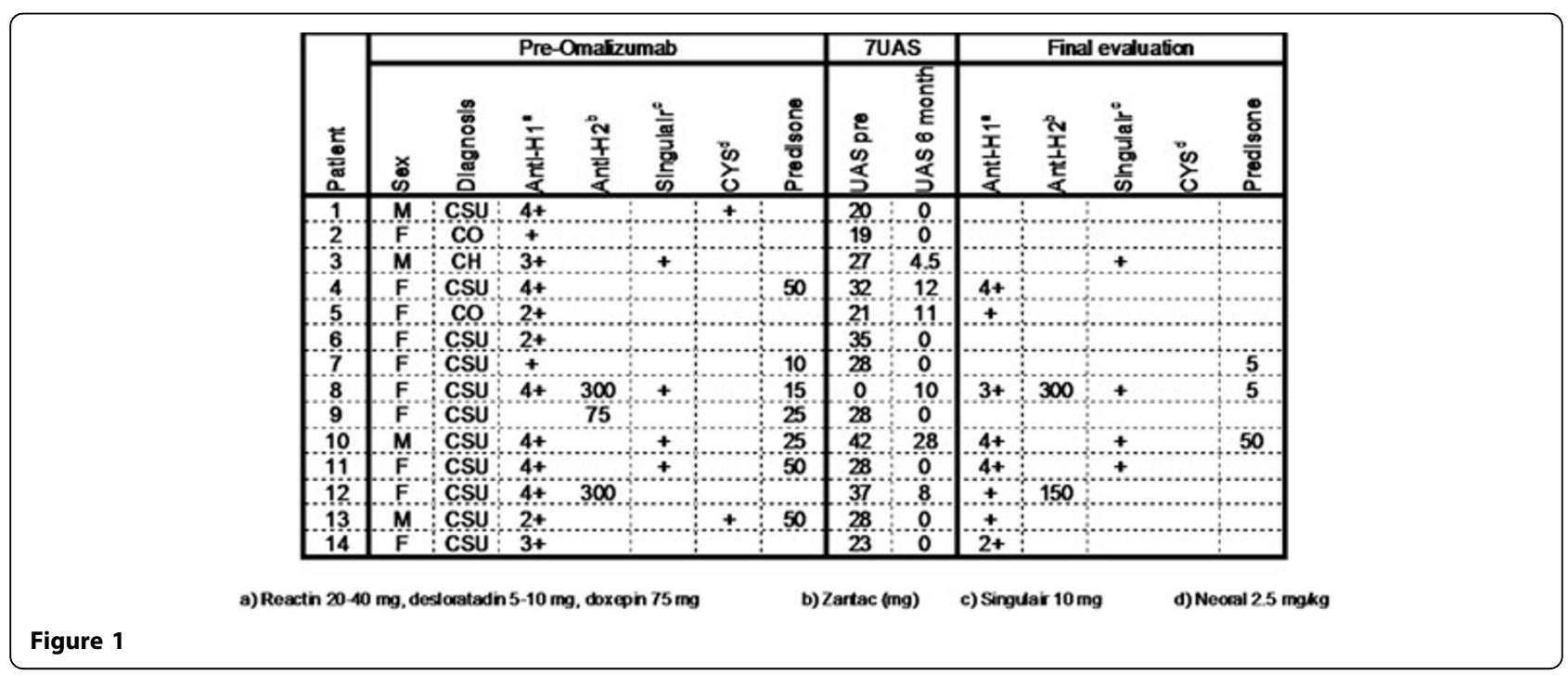

*Correspondence: hebert.j@videotron.ca

'Centre de recherche appliquée en allergie de Québec, Québec City, Canada

Full list of author information is available at the end of the article 
6 month observation (Figure 1). 7UAS in patient \#8 was $>30$ previously but $=0$ at entry because treated with oral prednisone for $>1$ year. The response was not satisfactory for patient \# 10 and omalizumab increased to $300 \mathrm{mg}$ after 6 months with a better clinical response (not shown). Along with the clinical improvement, the concomitant medications could also be reduced significantly in all patients except \#10, particularly prednisone.

\section{Conclusion}

Our results show that omalizumab improves significantly recommended treatment-resistant urticaria patients $(13 / 14)$ in terms of clinical symptomatology (7UAS) and drug reduction in a real life setting. None of the patients reported any adverse effect.

\section{Author details}

${ }^{1}$ Centre de recherche appliquée en allergie de Québec, Québec City, Canada. ${ }^{2}$ Allergie et Immunologie, CHUQ/Université Laval, Québec City, Canada.

Published: 2 November 2012

Cite this article as: Hébert and Caron-Guay: Effects of omalizumab on

chronic urticaria not responding to recommended therapy. Allergy,

Asthma \& Clinical Immunology 2012 8(Suppl 1):A17.

Submit your next manuscript to BioMed Central and take full advantage of:

- Convenient online submission

- Thorough peer review

- No space constraints or color figure charges

- Immediate publication on acceptance

- Inclusion in PubMed, CAS, Scopus and Google Scholar

- Research which is freely available for redistribution

Submit your manuscript at www.biomedcentral.com/submit
C Biomed Central 